\title{
Membership Survey of the
}

\section{Australasian College of Legal Medicine}

\section{Quality Assurance}

\author{
Authors: Beran Roy $\mathbf{G}^{1,2,3}$ \\ MD, FACLM, FRACP, FRCP, FFFLM (Hon) \\ Djekic, Sanja ${ }^{2}$ (Liverpool Hospital, Area Data Management) \\ B Comm, Grad Cert. Biostat \\ Bishop, Robert ${ }^{1}$ (ACLM Administrative Officer) \\ Dip AS \\ 1. Australasian College of Legal Medicine \\ 2. Liverpool Hospital/University of New South Wales \\ 3. Griffith University, School of Medicine, Queensland
}

Key Words:

Legal Medicine

Forensic Medicine

Quality Assurance 


\section{Introduction:}

The Council of the Australasian College of Legal Medicine (ACLM) considered it timely to survey its membership to determine how to best accommodate its members' needs.

\section{Methods:}

A questionnaire was devised, piloted and circulated amongst the 219 College members (excluding the 13 Honorary Fellows). Yield was maximised with 4 direct mailings, 4 questionnaire insertions in the quarterly College newsletter, 3 targeted emails and follow-up phone calls.

\section{Results:}

The survey achieved 160 (73\%) response rate of whom $\sim 40 \%$ were substantially involved in legal and forensic medicine and $\sim 40 \%$ were occasionally involved. Thirty-five (23\%) specialised in forensic medicine and 101 (63\%) held Fellowship status in other recognised medical specialities. Equal $1 / 3$ of the members had been so for $>10$ years, $5-10$ years or $<5$ years, demonstrating the dynamic nature of the College. Of them 53\% were Fellows, $26 \%$ Members and $21 \%$ Associates with $50 \%$ of the latter groups willing to train towards Fellowship. About half the respondents (48\%) regularly attended the Annual Scientific Meeting (ASM) and favoured the Eastern border for such meetings. The collegiate nature of the College was deemed its most positive aspect with a dichotomy of views regarding seeking alternative strand affiliation for specialist recognition, although $80 \%$ indicated they would retain College membership even if such affiliation occurred. Those who attended College educative programs found them useful but attendance was between $32-49 \%$, depending on the course.

\section{Discussion:}

There appeared widespread satisfaction with College performance and activities but a low uptake of educative courses, other than Annual Scientific Meetings, thereby identifying marketing of courses as needing extra attention. 
The Australasian (previously Australian) College of Legal Medicine (ACLM) was founded more than $1 \frac{112}{2}$ decades ago ${ }^{(1)}$, incorporating clinicians dually qualified in medicine and law and those with post-graduate forensic medicine training and experience ${ }^{(2)}$. It sought to provide an umbrella organisation, as a specialised medical College servicing the needs of those in legal and forensic medicine, to offer leadership and educational direction to its membership ${ }^{(1)}$.

The Council of the College felt that the time had arrived when it was appropriate to evaluate the purpose and direction of the College. It was considered opportune to conduct a plebiscite of the membership to determine whether the aims and orientation of the College remained apposite to the needs and aspirations of the members.

This paper reports the findings of this survey, designed to assist the College Council to best accommodate the needs of its constituents within the College.

\section{METHODS}

At its Council meeting, in December 2009, the ACLM Council voted to conduct a study within the College, designed to ensure that the College remained relevant to its membership. A three-man-Committee, within the twelve-person-Council, devised a questionnaire that was piloted within the Council to satisfy clarity, consistency and relevance of format and content. Membership of the College was 232, of whom 13 were Honorary Fellows, hence not included within the study population.

The survey was distributed to the remaining 219 College members with 4 direct mailings to each of the members, 4 inclusions within the quarterly College newsletter, 3 targeted emails to non-responders complemented by direct telephone calls to recalcitrant members.

Each survey had a specific number known only to the Administrative Officer (AO) of the College and non-disclosed to those analysing the data, to preserve respondent anonymity. Those identified by the $\mathrm{AO}$ as non-responders were followed to enhance response rate until it was deemed counterproductive to relations with those members. It was felt that $a>80 \%$ response rate was the preferred target but that a response rate of $\geq 70 \%$ would still suggest a fairly representative sample. To achieve this response rate required 40 direct phone calls to non-responding members, not all of whom could be contacted.

\section{RESULTS}

Consequent to the various approaches, responses were obtained from: 69 members as a result of the mailings; 47 from inclusion of the questionnaire within the quarterly College newsletter; 16 from personal email approach; and 28 following telephone approach. The 160 respondents, $73 \%$, was achieved with the AO ensuring every attempt had been made to contact all ACLM members and that no-one had responded more than once. 
Respondents were asked to identify their involvement in legal medicine (Figure 1), of whom $35(23 \%)$ specialised in forensic medicine or pathology. Of the doctors surveyed, $3(2 \%)$ worked as barristers rather than medical/dental clinicians despite being dual qualified in medicine/dentistry and law. The remaining sample were distributed in various medical disciplines with only $16(10 \%)$ being identified as general practitioners. One hundred and one (63\%) were identified as holding fellowship in other Australian Medical Council recognised speciality colleges, other than the ACLM.

The membership was evenly divided amongst those who had $\geq 10$ year's College membership (31\%), $5-9$ years College membership $(33 \%)$, and $<5$ years membership (36\%). Of respondents, $53 \%$ were Fellows, $26 \%$ Members and $21 \%$ Associates of the College. Of the 75 (47\%) not holding College Fellowship, half 37 $(49 \%)$ were willing to undertake the requisite training and examination to become Fellows. Of those unwilling to pursue further training towards Fellowship, 10 (27\%) nominated time requirements as the limiting factor with either retirement or near retirement being the major reasons why others were unwilling to undertake further studies. Only 7 of $38(18 \%)$ of those unwilling to seek Fellowship indicated that their lack of motivation to proceed was predicated by lack of professional need to so advance.

The value of College courses was investigated with half (78) of the respondents having completed the Basic Law Intensive, which is a College designed course, run over 2 days, to introduce members to legal thinking. Of them $54(69 \%)$ found the course very useful and a further $19(24 \%)$ found it of marginal benefit. Of the 51 (32\%) who had completed the Practical Law Intensive, a 2 day College designed course more specifically aimed at the areas of direct interface of medicine and law, $48(85 \%)$ found it to be either very useful, [38 (75\%)] or of marginal benefit [10, (20\%)]. Of the 71 (44\%) completing an Expert Witness Training Course, 65 (92\%) found it either very useful, [53 $(75 \%$ ] or of marginal beneficial [12 $(17 \%)]$.

At the time of preparing the survey, some within the College were seeking specialist recognition via Australian Medical Council approved specialist Colleges. When asked if the respondents would retain ACLM membership, if these overtures were successful, $128(80 \%)$ answered in the affirmative while $29(18 \%)$ were undecided and only $3(2 \%)$ indicated that they would definitely relinquish College membership. Of the 31 (20\%), who were undecided or would opt out, factors that might influence the decision included: need for further study, impending retirement; college direction; work requirements; role played by the ACLM in any possible amalgamation; and interest at the time.

Attendance at the College Annual Scientific Meeting (ASM) was: always for $14(9 \%)$; sometimes for $62(39 \%)$ and occasionally for 18 (11\%). A quarter [37 (23\%)] never attended the ASM and $29(18 \%)$ rarely did so. Of those who have not always attended, 60 respondents cited other commitments as precluding attendance and 42 were deterred by conference location. Other criticisms included: program relevance; time of notification; costs; program content and personal issues, such as ill health or retiring. Asked the favoured location of the ASM, in order of preference the top five locations were: Sydney, Melbourne, Canberra, Brisbane and Adelaide.

Respondents were asked to nominate those factors which positively influenced their affiliation with the College (Figure 2). The majority identified fellowship with likeminded people and scientific discussion as their most positive experiences. Asked 
what the College should change to become more appealing, the greatest emphasis was increased educative activities (Figure 3). Those areas that should attract less emphasis were 'ceremony' and less focus on forensic medicine but this question attracted a very small response rate $[(24(15 \%)]$, making it less than representative. Of the $99(62 \%)$ advocating change (mostly positive - Figure 3), the majority [77 $(78 \%)]$ would be willing to contribute actively to assist with the change.

Exploring the potential for strands of the College to become faculties of other colleges, $100(63 \%)$ supported moves by the forensic medicine strand to look further afield, 71 (45\%) were extremely supportive and 29 (18\%) marginally so. Conversely $27 \%$ were either ambivalent or non-supportive and $10 \%$ did not respond to this question. Of the 100 supporting the move, 88 would remain within the ACLM with 7 either undecided or negative and 5 non-responding. Asked what motivated their decision the most prevalent response was a need to better recognise forensic medicine (18). Considering the legal medicine strand, only 63 (39\%) were supportive of exploration with other colleges, a quarter, 38 (24\%) were ambivalent. $16(10 \%)$ opposed the move and a quarter, $42(26 \%)$ failed to respond. Of those who were supportive $54(90 \%)$ would remain in the College, the reason being that those within the College recognised the special focus necessary for legal medicine, which retains a need for proper clinical acumen in addition to administrative and legal skills.

\section{DISCUSSION}

This is the first plebiscite conducted by the ACLM, as a quality assurance to ascertain the views of its constituents and to determine if the College was satisfying the needs of its membership. The initial aim was to secure a yield of $80 \%$ response rate but a response rate of $73 \%$ (almost $3 / 4$ ) was still well beyond many similar studies with response rates below $50 \%(3-5)$. Every effort was made to maximise the yield, with the $\mathrm{AO}$ of the College the only person privy to the identification of respondents, to ensure targeted follow-up. Assessors of the data were blinded to the respondents' identities. The survey design did not lend itself to sophisticated statistical analysis, other than descriptive demography, but this was considered adequate for the purposes of the evaluation.

Of the respondents, $40 \%$ were substantially involved in legal or forensic medicine, with a similar number ( 40\%) occasionally so involved (Figure 1). This would suggest that while the College members have a significant interest in legal and forensic medicine, this need not be the principal focus of their clinical work. This concept is mirrored in the overall job descriptions (Table 1) in which College members identify themselves according to their clinical practices, rather than their roles within legal or forensic medicine. This reflects the diversity of clinical expertise within the College but should not be seen as a negative when considering legal and forensic medicine as specialist areas within their own domain of requisite knowledge. Almost $2 / 3(63 \%)$ of the College membership had Fellowship status in other recognised speciality Colleges, thereby attesting to the vast experience encompassed within the ACLM. The scope of legal and forensic medicine is such that it encompasses a vast array of other disciplines which are requisite to adequately satisfy the interface of medicine and law ${ }^{(2)}$.

Being a relatively new College, the question emerged whether the membership was a static body of older clinicians who obtained College membership via the provision of "grandfathering" as existed at the outset of its establishment. The fact that equal 
proportions were represented by the categories $>10$ years, $5-9$ years and $<5$ years College membership would dispel this notion, therefore confirming the College as a dynamic and viable institution. Similarly, the fact that half the respondents, who had not achieved Fellowship of the College, were prepared to pursue Fellowship status would suggest that the College retained a dynamic motivation for advancement within the College.

Two issues emerged regarding the value, or otherwise, of College educative courses. The fact that only half the cohort had completed Basic Law Intensive, only a third the Practical Law Intensive and less than a half the Expert Witness Program, causes some concern for the organisers. This is particularly so when considered in the light of the majority of $93 \%, 95 \%$ and $92 \%$ (respectively), claiming them to be useful experiences and of whom $64 \%, 75 \%$ and $75 \%$ found them very useful. These conflicting data would suggest that the courses are of merit but that their value has not been adequately championed. The hierarchy of the College will need to reconsider how these courses are marketed to its constituents. When courses are poorly attended, but very useful, the fault should rest with the marketing process ${ }^{(3)}$, which needs to be addressed.

About half the sample regularly attended the ASM, reinforcing the collegiate nature of the College. Reasons for not attending were of a personal nature rather than directed against the College. Attendances at the last 3 ASM, held in Adelaide and Sydney in Australia (2009 and 2010 respectively) and Queenstown, New Zealand in 2011 , were of the order of $30 \%$, which is a fairly impressive rate of attendance.

There appeared a significant dichotomy between the legal medicine and forensic medicine strands within the College, with regard to seeking alternative affiliations with craft groups. There was strong support from those in forensic medicine to seek alternative avenues to achieve specialist recognition. Even so, the majority (80\%) indicated that they would retain College membership thus suggesting that the College offered more than purely vocational recognition. It provided a collegiate body of like-minded individually, which offered a vehicle beyond simple craft recognition.

One hundred (63\%) supported the move for forensic physicians, while only $63(39 \%)$ favoured similar moves for the legal medicine strand, to seek affiliation with other colleges to achieve specialist recognition. This may well reflect the nature of the clinical practices, with the majority of those within the legal medicine strand already holding specialist recognition from other approved colleges. It would follow that these members had little to gain from further specialist recognition while those in forensic medicine were not afforded appropriate recognition in any state other than Queensland, where an FACLM is a prerequisite for appropriate employment.

\section{CONCLUSION}

This survey has demonstrated that in large respect the College is satisfying the needs of its members. Even those keen to explore avenues for easier specialist recognition, by the craft group becoming an approved faculty of an established "Royal College", have indicated that they would retain College membership because of what the College has to offer beyond vocational recognition. It is impossible to comment on the views and aspirations of those who did not respond to the survey although the yield from the study was well beyond that 
from comparable surveys and hence the response rate should be considered to represent an a acceptable overview of those within the College. A negative to emerge from the survey has been an acknowledgement that the training courses run by the College, are poorly attended. This suggests the College Council should explore better marketing strategies to enhance their uptake and attendance.

\section{REFERENCES:}

1. Beran R G

"The teaching of legal medicine in Australasia" J Forensic \& Legal Med 49: SP7, 2006

2. Beran $\mathrm{R} G$

"Analysis - What is legal medicine?"

J Forensic Legal Med 15 (3): 158 - 162, 2008

3. Kalib I S

"Marketing your legal services"

$1^{\text {st }}$ Edition, K \& A Press, p8, 1993 
FIGURES AND TABLES:

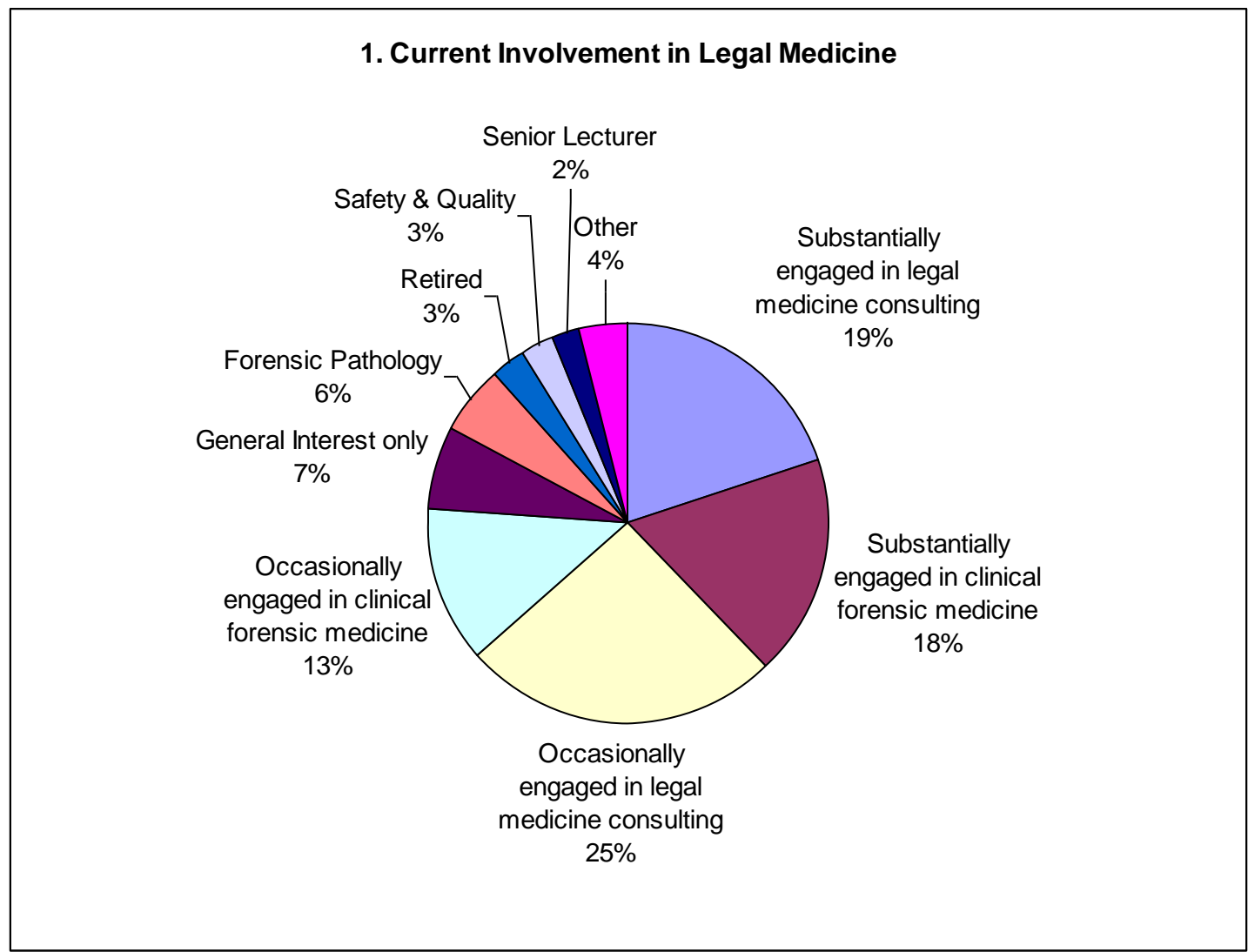

Figure 1.

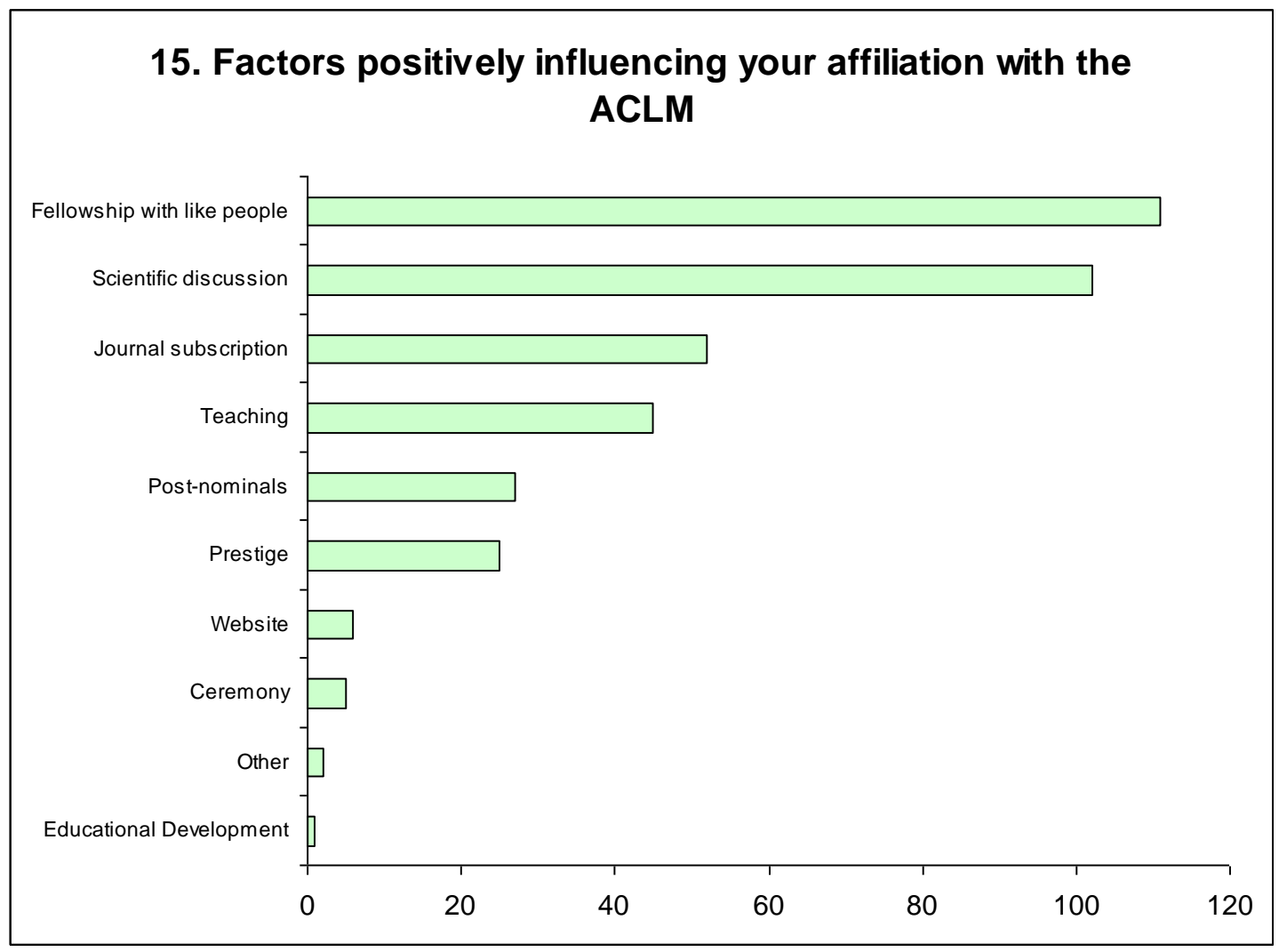

Figure 2. 


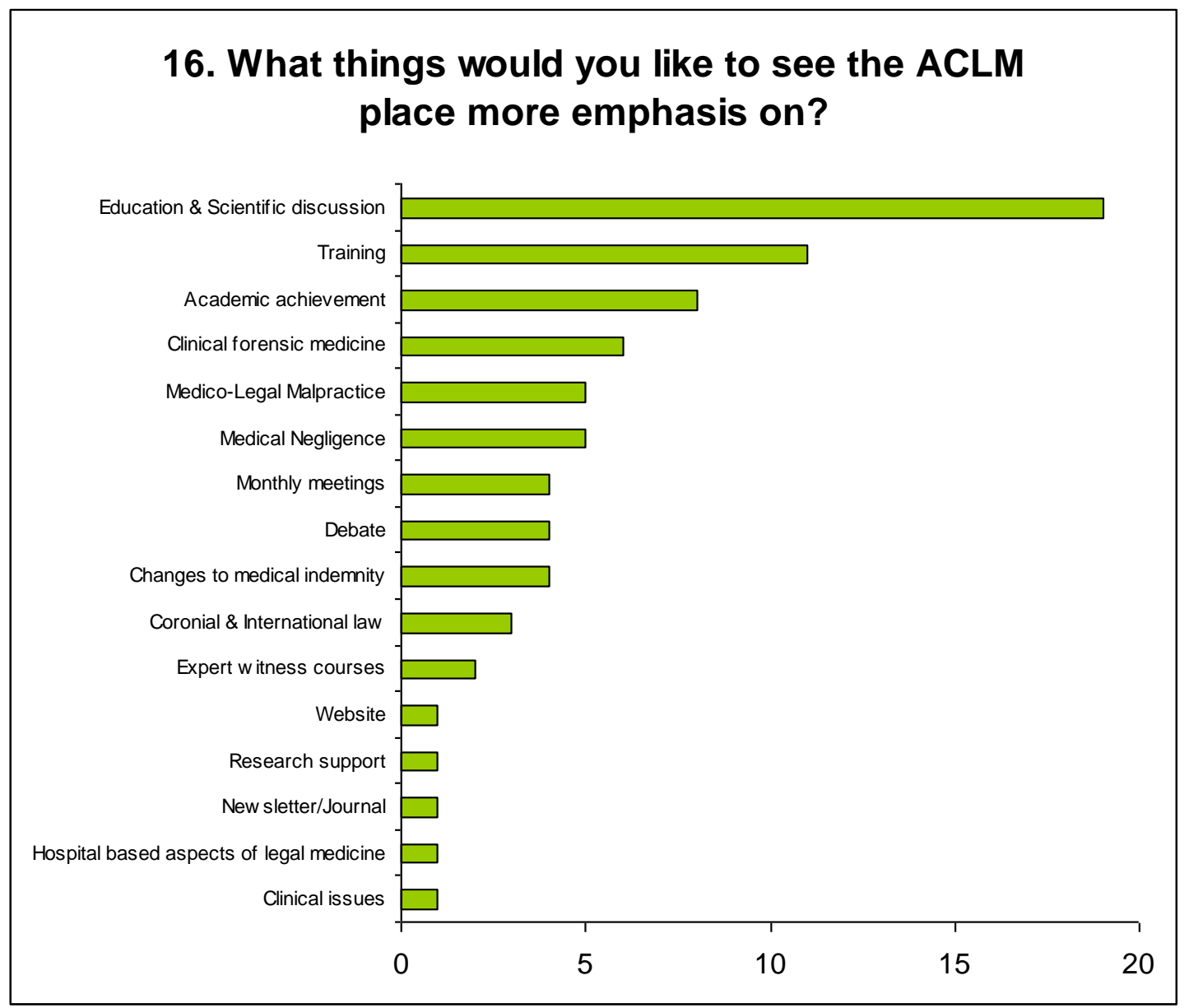

Figure 3.

\begin{tabular}{|l|r|r|}
\multicolumn{1}{l}{ Job Description } & Total & Percentage \\
\hline Forensic Medicine & 31 & $19 \%$ \\
\hline Physician/Medical Officer & 26 & $16 \%$ \\
\hline General Practitioner & 16 & $10 \%$ \\
\hline Medico Legal Practitioner & 14 & $9 \%$ \\
\hline Surgeon/Neurosurgeon & 13 & $8 \%$ \\
\hline Other Specialist & 12 & $8 \%$ \\
\hline Psychiatrist & 7 & $4 \%$ \\
\hline Dentist/Dental Surgeon & 6 & $4 \%$ \\
\hline Retired & 5 & $3 \%$ \\
\hline Medical Adviser & 4 & $3 \%$ \\
\hline Pathologist & 4 & $3 \%$ \\
\hline Sexual Assault & 4 & $3 \%$ \\
\hline Child Protection/Paediatrics & 4 & $3 \%$ \\
\hline Occupational Medicine & 4 & $3 \%$ \\
\hline Other & 4 & $3 \%$ \\
\hline Barrister & 3 & $2 \%$ \\
\hline Sexual Health & 3 & $2 \%$ \\
\hline
\end{tabular}

\section{Table 1.}

